\title{
Inactivation of ventral hippocampus projections promotes sensitivity to changes in contingency
}

\author{
Jacqueline M. Barker, ${ }^{1}$ Kathleen G. Bryant, ${ }^{2}$ and L. Judson Chandler ${ }^{2}$ \\ ${ }^{1}$ Department of Pharmacology and Physiology, College of Medicine, Drexel University, Philadelphia, Pennsylvania \\ 19102, USA; ${ }^{2}$ Department of Neuroscience, Medical University of South Carolina, Charleston, \\ South Carolina 29425, USA
}

\begin{abstract}
The loss of behavioral flexibility is common across a number of neuropsychiatric illnesses. This may be in part due to the loss of the ability to detect or use changes in action-outcome contingencies to guide behavior. There is growing evidence that the ventral hippocampus plays a critical role in the regulation of flexible behavior and reward-related decision making. Here, we investigated the role of glutamatergic projections from the ventral hippocampus in the expression of contingencymediated reward seeking. We demonstrate that selectively silencing ventral hippocampus projections can restore the use of action-outcome contingencies to guide behavior, while sparing cue-guided behavior and extinction learning. Our findings further indicated that the ability of the ventral hippocampus to promote habitual response strategies may be in part mediated by selective projections from the ventral hippocampus to the nucleus accumbens shell. Together these results implicate glutamatergic projections from the ventral hippocampus in the regulation of behavioral flexibility and suggest that alterations in ventral hippocampus function may contribute to overreliance on habitual response strategy observed in neuropsychiatric illnesses including addiction and obsessive-compulsive disorder.
\end{abstract}

The ability to flexibly regulate behavior is critical for successful navigation of ever-changing environments. The loss of behavioral flexibility can be modeled by the transition from goal-directed actions to habitual behavior. Goal-directed reward-seeking behaviors are defined as those that are driven by action-outcome relationships and are therefore sensitive to changes in contingency. Over time and repeated performance, habitual response strategies may dominate behavior (Everitt and Robbins 2015; Barker and Taylor 2016). In these conditions, behavior is no longer sensitive to changes in action-outcome contingency, and rather is elicited by stimuli. While in many conditions the development of habits can be advantageous by freeing cognitive resources, under certain conditions reliance on habitual response strategies can become maladaptive and maintain problematic behavior. For example, deficits in behavioral flexibility are common in multiple neuropsychiatric illnesses such as obsessive-compulsive disorder and alcohol use disorders in which patients show an overreliance on habitual response strategies (Sjoerds et al. 2013; Gillan et al. 2015).

The expression of goal-directed actions and habitual behaviors is subserved by distinct neural circuitry. Much research has focused on the role of prefrontal and striatal structures in habits. In particular, prelimbic and infralimbic prefrontal cortex (PFC) subregions have distinct contributions to response strategy selection (Smith and Graybiel 2013). Prelimbic PFC is required for the acquisition, but not expression, of goal-directed actions (Killcross and Coutureau 2003; Tran-Tu-Yen et al. 2009), while infralimbic PFC is necessary for habitual reward seeking (Coutureau and Killcross 2003; Smith et al. 2012; Barker et al. 2017). Similarly, the dorsomedial striatum, which receives substantial projections from the prelimbic PFC, is necessary for the expression of goal-directed actions (Yin et al. 2005). In contrast, the dorsolateral striatum has a similar role to the infralimbic PFC in habitual behavior, and is necessary

\section{Corresponding author: barker.jacqui@gmail.com}

Article is online at http://www.learnmem.org/cgi/doi/10.1101/lm.048025. 118. for the expression of habitual reward seeking (Yin et al. 2004, 2006).

While these structures have well-established roles, it is becoming appreciated that structures outside of corticostriatal circuits additionally contribute to response strategy selection. Recent research has implicated ventral hippocampal plasticity in the acquisition and expression of habitual behavior (Barfield et al. 2017). In particular, Barfield and colleagues demonstrate that overreliance on habitual response strategies in a rodent model of adolescent stress are accompanied by a loss of full-length tyrosine kinase receptor B (trkB) expression, and further, that this deficit could be rescued by overexpression of trkB within the ventral hippocampus. Though much research into the role of the hippocampus as a whole has focused on its contribution to spatial and contextual learning and memory and mnemonic processing, there is a growing appreciation of the separable contributions of the ventral and dorsal subregions (Pennartz et al. 2011). A critical role for the ventral portion of the hippocampus has been identified in the regulation of decision-making and reward-seeking behavior, including regulation of approach/avoidance behavior (Ito and Lee 2016) and contextual memory retrieval (Riaz et al. 2017). Despite this growing evidence of a likely role for the ventral hippocampus in regulation of response strategy, minimal research has investigated the direct contribution of ventral hippocampus projections to the expression of behaviors that are insensitive to action-outcome contingencies. Here, we investigated how putative glutamatergic projection neurons in the ventral hippocampus may contribute to the expression of habitual response strategies. We further identify a selective role for ventral hippocampus projections to the nucleus accumbens in the regulation of response strategy.

(C) 2019 Barker et al. This article is distributed exclusively by Cold Spring Harbor Laboratory Press for the first 12 months after the full-issue publication date (see http://learnmem.cshlp.org/site/misc/terms.xhtml). After 12 months, it is available under a Creative Commons License (Attribution-NonCommercial 4.0 International), as described at http://creativecommons.org/licenses/ by-nc/4.0/. 


\section{Results}

Silencing ventral hippocampus projections restores sensitivity to change in contingency

To determine whether inhibition of ventral hippocampus projections mediated sensitivity to contingency degradation, mice $(n=20)$ expressing the Gi-coupled DREADD in the ventral hippocampus were trained to self-administer sucrose (Fig. 1A,B). Mice acquired the lever press contingency and discriminated between active and inactive levers (rmANOVA: $\left.F_{(1,17)}=28.76, P<0.001\right)$ and escalated responding across training (Fig. 1C) (main effect of day, $F_{(1.951,33.174)}=16.331, P<$ 0.001; Greenhouse-Geisser corrected; lever $\times$ day interaction: $\quad F_{(2.123,36.099)}=$ 14.127, $P<0.001$; Greenhouse-Geisser corrected). After training, mice underwent degraded and nondegraded test sessions $30 \mathrm{~min}$ after receiving counterbalanced injections of either $\mathrm{CNO}$ or saline. Results indicated a degradation $\times$ drug interaction (Fig. 1D; $F_{(1,19)}=5.743$, $P<0.05)$, as well as a main effect of degradation $\left(F_{(1,19)}=11.006, P<0.01\right)$. No main effect of drug was observed $\left(F_{(1,19)}=\right.$ $0.091, P=0.766$ ). Post-hoc analyses revealed that during saline test conditions, responding was not sensitive to changes in contingency $\left(t_{(19)}=0.943, \quad P>0.4\right)$. However, under CNO testing conditions in which ventral hippocampus projections were silenced, mice reduced responding whenever the contingency was degraded $\left(t_{(19)}=3.356, P<0.05\right)$, suggesting that $\mathrm{CNO}$ selectively reduced responding. Of note, response rates in the degraded test session in which animals received CNO were not significantly different from the saline test session in which the contingency was degraded. This suggests that changes in response rate during the nondegraded test session in which the ventral hippocampus is silenced may partially mediate this effect. Thus,

the current findings demonstrate that under conditions in which ventral hippocampus function is intact, response rates are not modulated by change in action-outcome contingency. However, when ventral hippocampus projections are silenced, response rates are different in sessions in which the contingency is intact (nondegraded) versus when it is degraded.

Because reinforcer delivery was matched to each animal's own performance, reinforcer delivery rates did not differ between degraded and nondegraded test sessions. rmANOVA indicated no main effects of drug $\left(F_{(1,18)}=0.767, P=0.393\right)$, contingency degradation $\left(F_{(1,18)}=1.046, P=0.32\right)$, or degradation $\times$ drug interactions $\left(F_{(1,18)}=0.785, P=0.387\right)$.

Although drug and test order was counterbalanced to negate any potential order effects on these within subjects comparisons, these data were separately analyzed using test order and drug order as independent factors. This analysis revealed a significant degradation $\times$ drug interaction is still present $\left(F_{(1,16)}=6.611, P=0.021\right)$.
No four-way interaction (drug $\times$ degradation $\times$ test order $\times$ drug order: $\left.F_{(1,16)}=2.474, P=0.135\right)$ was present. No three-way interactions were observed (drug $\times$ degradation $\times$ drug order: $F_{(1,16)}=0.103, P=0.752$; drug $\times$ degradation $\times$ test order: $F_{(1,16)}=$ 0.915, $P=0.353$; drug $\times$ test order $\times$ drug order: $F_{(1,16)}=0.638, P=$ 0.436 ; drug $\times$ test order $\times$ drug order: $\left.F_{(1,16)}=1.131, P=0.303\right)$. However, in addition to the significant drug $\times$ degradation interaction, two-way interactions between the effects of drug and drug order $\left(F_{(1,16)}=19.436, P<0.001\right)$ and between degradation and test order $\left(F_{(1,16)}=8.670, P=0.01\right)$ were observed. No interaction between drug and test order $\left(F_{(1,16)}=0.276, P=0.606\right)$, degradation $\times$ drug order $\left(F_{(1,16)}=0.909, P=0.354\right)$, or test order $\times$ drug order $\left(F_{(1,16)}=0.00, P=0.999\right)$ were present. No main effects of test order or drug order were present $\left(F_{(1,16)}=2.590, P=0.127 ; F_{(1,16)}=0.591\right.$, $P=0.453$; respectively). To further deconstruct the interactions between drug and drug order, and test and test order, post-hoc comparisons were performed. Post-hoc analyses indicate that test order 
did not impact response rates for responding in CNO testing conditions (uncorrected $P=0.428$ ). However, response rates during saline test conditions were higher if mice were tested in the saline testing condition first (uncorrected $P=0.002$ ), suggesting that having previously been tested in the CNO condition resulted in lower response rates overall in the saline test sessions. Further, test order impacted response rates such that if the nondegraded test session occurred first, response rates in the nondegraded test sessions were higher than if the nondegraded test session occurred second (uncorrected $P=0.01)$. However, the order of test session did not impact response rates in the degraded test sessions (uncorrected $P=0.335$ ). Together, these findings indicate that while test order can impact overall response rates, it does not do so in a way that impacts the degradation test by drug interaction.

\section{Inhibition of the ventral hippocampus did not impact licking behavior during contingency degradation testing} To determine if inhibition of putative glutamatergic neurons in the ventral hippocampus regulated licking behavior in general, we examined licking during degraded and nondegraded test sessions. No effect of CNO administration $\left(F_{(1,18)}=0.049, P=0.827\right)$, contingency degradation $\left(F_{(1,18)}=2.312, P=0.146\right)$, nor CNO administration $\times$ contingency degradation interaction $\left(F_{(1,18)}=0.013, P=\right.$ 0.912) was observed, indicating that inhibition of the ventral hippocampus did not impact reward consumption (Fig. 1E).

\section{CNO administration does not impact response strategy selection in mice lacking the Gi-DREADD}

To determine if CNO impacted sensitivity to change in contingency independent of Gi-DREADD activation in the ventral hippocampus, a separate cohort of animals $(n=5)$ received a microinfusion of a control virus expressing YFP in the ventral hippocampus. Mice were trained to self-administer sucrose in the absence of $\mathrm{CNO}$, and escalated responding across acquisition (Fig. 2A; $F_{(2.691,10.763)}=4.952, P<0.05$; Greenhouse-Geisser corrected) and discriminated between active and inactive levers (main effect of lever: $F_{(1,4)}=26.344, P<0.01$; lever $\times$ day interaction: $F_{(2.569,10.276)}=3.977, P<0.05$; Greenhouse-Geisser corrected). After response acquisition, mice received an injection (i.p.) of either $\mathrm{CNO}$ or saline prior to degraded and nondegraded test sessions in a counterbalanced fashion. Analysis of this data indicated there was no main effect of $\mathrm{CNO}$ (Fig. $2 \mathrm{~B} ; F_{(1,4)}=0.318, P=0.603$ ) or drug $\times$ degradation interaction $\left(F_{(1,4)}=2.737, P=0.173\right)$ in mice lacking DREADD expression, nor was there any main effect of contingency degradation $\left(F_{(1,4)}=0.362, P=0.580\right)$.
A

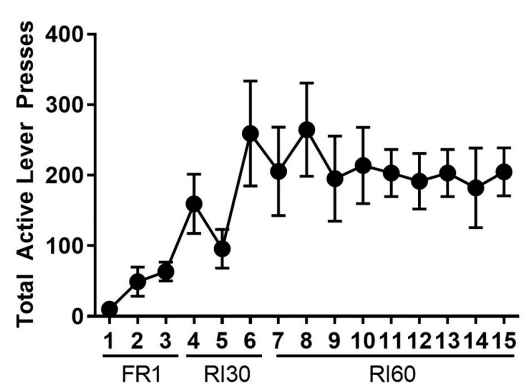

B

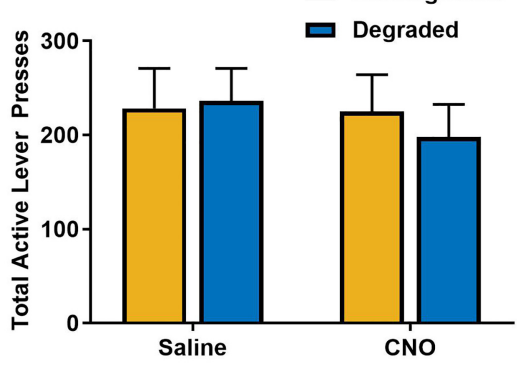

Figure 2. CNO administration does not impact response strategy in animals lacking the DREADD receptor. $(A)$ To confirm that off-target effects of CNO did not mediate the observed role for ventral hippocampus in response strategy selection, a cohort of mice received an injection of a virus that did not contain the Gi-DREADD and were trained to self-administer sucrose under the same conditions. (B) Administration of CNO in mice that did not express the Gi-DREADD in the ventral hippocampus did not mediate response strategy selection.
Silencing ventral hippocampus projections did not impact expression of cue-guided licking behavior

To determine if inhibition of ventral hippocampus projections generally impacted the use of established contingencies to guide behavior, we investigated discrimination in sucrose consumption during the presence of a reward predictive cue after systemic administration of $\mathrm{CNO}$ or saline in mice expressing the Gi-coupled DREADD in the ventral hippocampus. Our results indicate that acute silencing of putative glutamatergic projection neurons in the ventral hippocampus did not impact the use of established stimulus-outcome contingencies to guide consummatory behavior. Mice exhibited greater licking behavior during the presentation of a reward-paired cue (Fig. 3A; rmANOVA; $F_{(1,5)}=9.765, P<$ $0.05)$, but no main effect of $\mathrm{CNO}\left(F_{(1,5)}=0.126, P=0.737\right)$ or $\mathrm{CNO} \times$ cue interaction $\left(F_{(1,5)}=0.013, P=0.915\right)$ were observed.

In order to determine if silencing ventral hippocampus projections impacted conditioned responding independent of unconditioned licking behavior, we analyzed licking behavior during the first cue presentation during each test session when no sucrose was present prior to reward presentation. Our data indicate no main effect of reward delivery (rmANOVA; $F_{(1,5)}=2.348, P=0.186$ ), main effect of $\mathrm{CNO}\left(F_{(1,5)}=1.345, P=0.299\right)$, nor a $\mathrm{CNO} \times$ reward interaction $\left(F_{(1,5)}=3.485, P=0.121\right)$.

\section{Acquisition of extinction was not influenced by silencing ventral hippocampus projections}

To determine if ventral hippocampus projections were involved in the acquisition of extinction of sucrose seeking, a subset of mice expressing the Gi-coupled DREADD were retrained under conditions in which the action-outcome contingency was intact. After stable responding, mice received either $\mathrm{CNO}$ or saline and underwent an extinction protocol. All mice reduced responding under extinction conditions (Fig. 3B; main effect of day: $F_{(1.550,18.594)}=$ 29.614, $P<0.001$; Greenhouse-Geisser corrected), but no effect of CNO administration $\left(F_{(1,12)}=0.384, P=0.547\right)$ or drug $\times$ day interaction $\left(F_{(1.550,18.594)}=0.362, P=0.648\right.$; Greenhouse-Geisser corrected) were observed.

\section{Selective silence of ventral hippocampus projections to the accumbens shell restores sensitivity to change in contingency}

To assess a selective role for ventral hippocampus to nucleus accumbens shell projections in the expression of contingency-insensitive behavior, a separate cohort of mice $(n=12)$ expressing the Gi-coupled DREADD in the ventral hippocampus underwent cannulation to target the nucleus accumbens shell (Fig. 4A-C). Mice were trained to self-administer sucrose in the absence of $\mathrm{CNO}$, and showed an escalation of responding across acquisition (Fig. $4 \mathrm{D} ; F_{(3.817,35.053)}=17.484, P<0.01$; Greenhouse-Geisser correction) and discriminated between active and inactive levers (main effect of lever; $F_{(1,11)}=$ 38.786, $P<0.01$; lever $\times$ day interaction; $F_{(2.981,32.794)}=14.625, \quad P<0.01$; Greenhouse-Geisser correction). After acquisition, mice received a microinfusion of CNO or saline targeting the nucleus accumbens shell 10 min prior to degraded and nondegraded test sessions in a counterbalanced order. Analysis of the results 
A

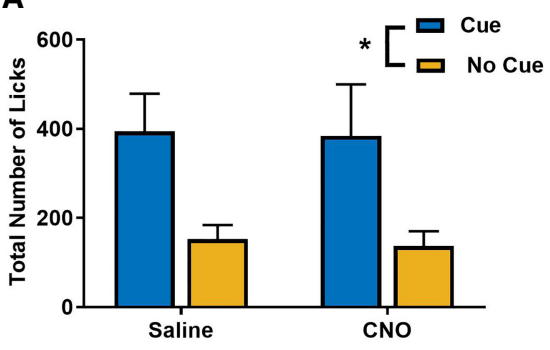

B

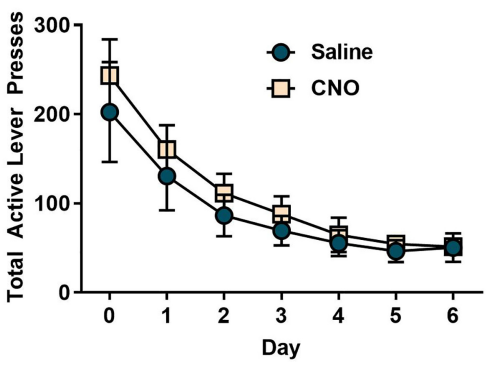

Figure 3. Effects of ventral hippocampus inhibition may be selective to contingency degradation. (A) To determine if inhibition of the ventral hippocampus prevented the use of cues to guide behavior, a subset of animals expressing the Gi-DREADD in the ventral hippocampus underwent Pavlovian conditioning in which a cue predicted sucrose delivery. Administration of $\mathrm{CNO}$ did impact the expression of cue-guided consummatory behavior. $(B)$ Inhibition of the ventral hippocampus did not impact the acquisition of extinction of sucrose seeking.

\section{Discussion}

The results of the present study identify a role for projection neurons from the ventral hippocampus in the expression of contingency-insensitive behaviors. Our findings indicate that after training under habit-promoting conditions, silencing of putative glutamatergic projections from the ventral hippocampus promotes the use of flexible, action-outcome contingency-mediated reward seeking (Fig. 1D). That is, in mice expressing the inhibitory Gi-DREADD in the ventral hippocampus, administration of the DREADD agonist CNO resulted in revealed a significant degradation $\times$ drug interaction (Fig. 4E; $F_{(1,11)}=6.443, P<$ $0.05)$, but no significant main effects of degradation $\left(F_{(1,11)}=0.148, P=0.708\right)$ or $\operatorname{drug}\left(F_{(1,11)}=3.907, P=0.074\right)$. Post-hoc comparisons indicate a significant difference in lever presses during the degraded versus nondegraded test when $\mathrm{CNO}$ was microinjected into the nucleus accumbens shell $\left(t_{(11)}=2.994, P<0.05\right)$. However, under saline testing conditions, no significant difference was observed between degraded and nondegraded conditions $\left(t_{(11)}=0.411, P>0.7\right)$.

Because reinforcer delivery during contingency degradation test sessions was matched to reinforcer delivery rates during control sessions, no differences in reinforcer delivery were observed. rmANOVA indicated no main effect of drug $\left(F_{(1,11)}=1.045, P=0.329\right)$ or degradation $\left(F_{(1,11)}=1.019, P=0.346\right)$, nor a drug $\times$ degradation interaction $\left(F_{(1,11)}=\right.$ $1.019, P=0.334)$.

\section{Selective inhibition of ventral hippocampus projections to the nucleus accumbens shell reduces licking behavior}

In order to determine if ventral hippocampus projections to the accumbens shell regulated reward consumption, we assessed licking behavior during contingency degradation and nondegraded test sessions. In contrast to systemic administration of $\mathrm{CNO}$, our findings indicated that selectively inhibiting the ventral hippocampus to nucleus accumbens shell during both degraded and nondegraded test sessions resulted in a reduction of licking behavior (main effect of drug; $\left.F_{(1,11)}=5.001, P=0.047\right)$. No main effect of degradation $\left(F_{(1,11)}=\right.$ 1.280, $P=0.282)$ nor drug $\times$ degradation interactions $\quad\left(F_{(1,11)}=0.457, \quad P=0.513\right)$ were observed (Fig. 4F).
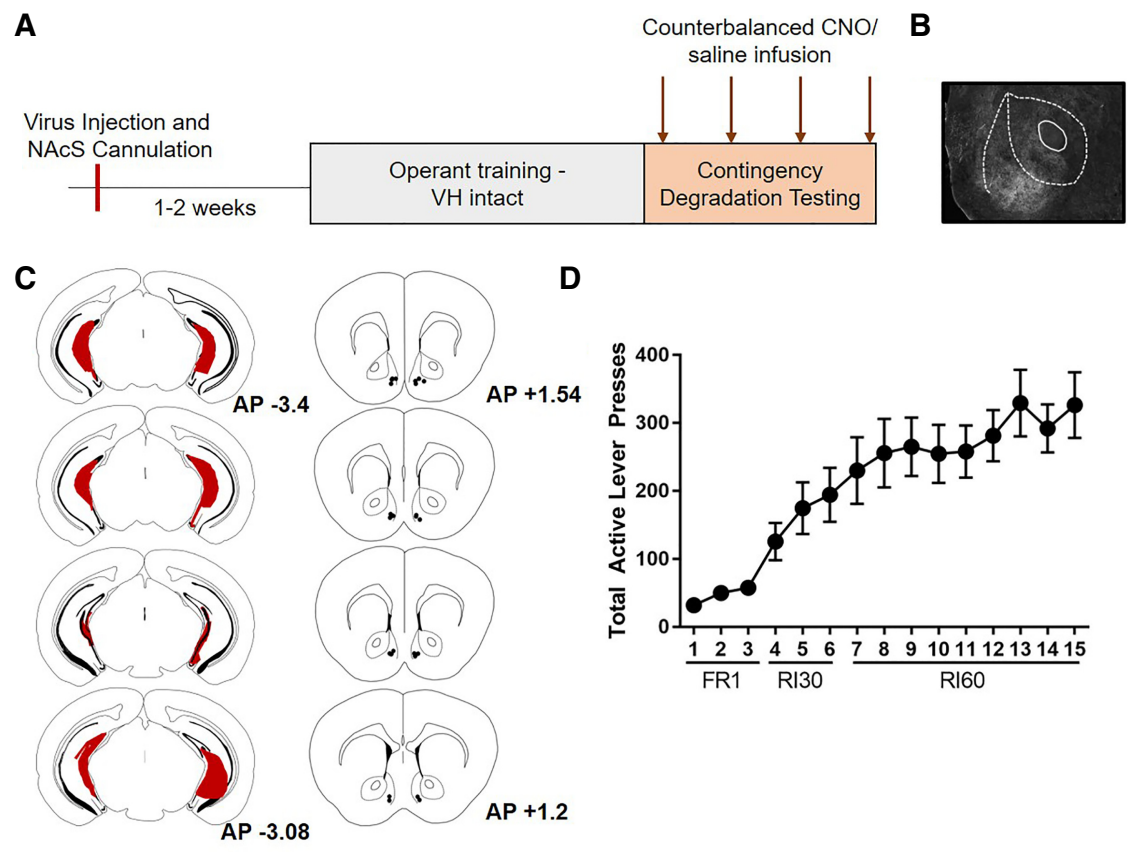

D

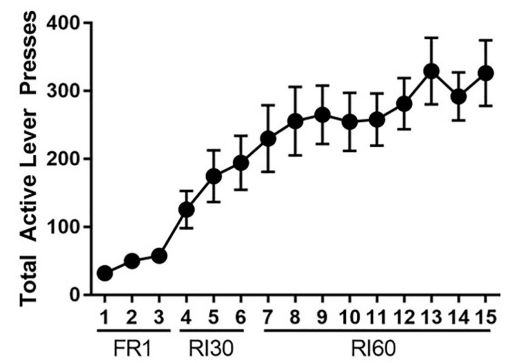

E

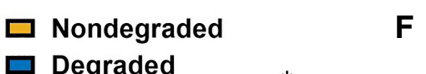

F $\square$ Nondegraded
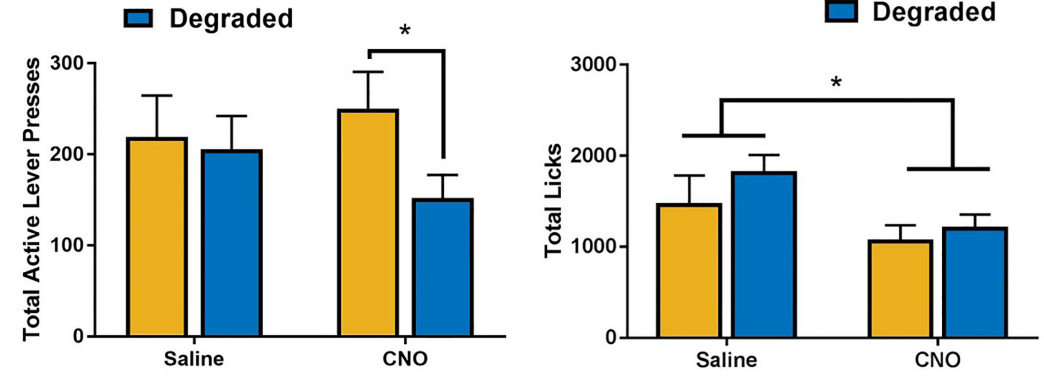

Figure 4. Selective inhibition of ventral hippocampus projections to the nucleus accumbens shell promotes the use of action-outcome contingencies. (A) Timeline of experimental procedures. Surgical and training procedures were identical to those described in Figure 1B, except that nucleus accumbens shell cannula were implanted at the time of surgery. (B) Photomicrgraph showing ventral hippocampus terminals within the nucleus accumbens. (C) Composite of injections indicating the spread of the Gi-DREADD within the ventral hippocampus (left) and accumbens cannula placements (right). $(D)$ Acquisition of sucrose seeking. $(E)$ Under control conditions, mice expressing the Gi-DREADD were insensitive to changes in action-outcome contingencies. Selective inhibition of the ventral hippocampus to nucleus accumbens shell promoted the use of action-outcome contingencies to mediate reward seeking. $(F)$ Selective inhibition of the ventral hippocampus to the nucleus accumbens shell reduces consummatory behavior in both nondegraded and degraded test sessions. 
reduced response rates when the action-outcome contingency was degraded. This may result from increased ability to detect the change in contingency, or from facilitated use of changes in contingency to guide behavior. This role for the ventral hippocampus appears to be distinct from the function of the dorsal hippocampus where loss of function results in an inability to detect changes in action-outcome contingency, potentially due to impairments in the ability to detect the rate of noncontingent reward delivery (Corbit and Balleine 2000).

Given the identified role of the ventral hippocampus in expression of habit-like response strategies, we investigated whether this was related either a role for the ventral hippocampus in promoting stimulus-mediated behavior, or detection of changes in contingency in general. To determine if the ventral hippocampus is required for the expression of cue-guided behavior, mice were trained to associate a cue with the delivery of a sucrose reward. Our data indicate that inhibition of ventral hippocampus projections did not impact the ability to use cues to guide consummatory behavior (Fig. 3A). Similarly, our data indicate that inhibition of the ventral hippocampus did not impact acquisition of extinction (Fig. 3B).

The ventral hippocampus sends substantial projections to the medial portion of the nucleus accumbens shell, and stimulation of these terminals can reinforce behavior (Britt et al. 2012). To determine if the nucleus accumbens is a downstream target that may mediate the actions of the ventral hippocampus in response strategy, we selectively inhibited these projections. Our results reveal a specific role for the ventral hippocampus to accumbens shell pathway in the regulation of response strategy (Fig. 4D). The ventral hippocampus and its projections to the nucleus accumbens shell have been predicted to contribute to determination of action plan values, in part by the assignment of a "value" to a given trial (Pezzulo et al. 2014). This suggests that the ventral hippocampus may promote insensitivity to changes in contingency by promoting performance of behaviors that previously resulted in reinforcement. We thus speculate that selective silencing of ventral hippocampus-nucleus accumbens shell projections during the loss of an established contingency may promote behavioral flexibility by reducing reliance on the cached value of an action on a given trial. This is consistent with recent findings that loss of normal BDNF signaling in the ventral hippocampus resulted in overreliance on habitual response strategies (Barfield et al. 2017), suggesting that reductions in ventral hippocampus plasticity may produce inflexible behavior. Our findings suggest that after acquisition of habitual response strategies, inhibition of ventral hippocampus may enable detection of changes in contingency, consistent with a role of ventral hippocampus-accumbens shell projections in the maintenance of previously reinforced behaviors.

Hippocampal projections to the nucleus accumbens have been reported to play a similar role in regulation of behavioral flexibility in latent inhibition "switching" models. In this model, the hippocampus compares established and new contingencies via projections to the nucleus accumbens and promotes response strategy "switching" when there is a high mismatch between old and new contingencies, but maintenance of current response strategies when there is low mismatch (Weiner and Feldon 1997). In the absence of the hippocampus, behavior is mediated entirely by current reward predictions (Weiner and Feldon 1997; Schmajuk et al. 2001; Ouhaz et al. 2014), which is similar to our findings in a contingency degradation test session. It is of interest that we did not observe an impact of silencing the ventral hippocampus on extinction learning. This may be because the "mismatch" between the established contingency and the extinction condition is sufficient for the hippocampus to promote "switching" behavior while reward prediction differences between the degraded and nondegraded test sessions are lower.
One caveat to consider in interpreting these findings is that it is possible that time spent consuming the reward could have differentially impacted behavior when the ventral hippocampus was silenced leading to alterations in response rates. However, because reinforcer delivery rates were matched between test conditions and because licking behavior was not increased during degraded test sessions, we do not think that this competing response contributed significantly to changes in response rate during sessions in which the contingency was degraded. Further, it is possible that inhibition of the ventral hippocampus promoted anticipatory checking for rewards during contingency degradation sessions. While we do not have data to demonstrate that this is the case, this increased reward seeking and checking is consistent in the use of contingencies to guide behavior, but not with facilitated detection of a changed contingency.

It is of interest that while systemic administration of CNO did not impact licking behavior either in a Pavlovian reward-seeking paradigm nor during contingency degradation test sessions, local administration of $\mathrm{CNO}$ within the accumbens shell to selectively inhibit ventral hippocampus-shell projections reduced licking behavior during both nondegraded and degraded test sessions (Fig. 4E). Of note, the assessment of cue-guided licking behavior did not assess licking that occurred prior to reward delivery, and it is possible that a shift in licking behavior patterns occurred that are not captured in these results. These findings are somewhat surprising given reports demonstrating that reductions of nucleus accumbens firing rates are requisite for consummatory behavior (Krause et al. 2010) and excitation of other glutamatergic projections to the shell have opposing effects on consummatory behavior (Millan et al. 2017). However, it is important to note that our study did not effectively discriminate between anticipatory licking behavior and consummatory licking behavior, and so it is possible that these results represent a shift in the pattern of licking behavior rather than a reduction in consummatory behavior surrounding reward delivery.

In addition to the nucleus accumbens shell, the ventral portion of the hippocampus has glutamatergic projections to a number of other structures that may contribute to its role in response strategy selection. For example, the ventral hippocampus innervates the orbitofrontal cortex (Ishikawa and Nakamura 2003), which has a known role in habitual behavior (Gourley et al. 2013; Gremel and Costa 2013). Lesions of the ventral hippocampus can mimic some of the effects of orbitofrontal lesions, including impairments in reversal learning, suggesting that the role of ventral hippocampus in promoting the use of previously established contingencies may be mediated, at least in part, by projections to the orbitofrontal cortex (Gourley et al. 2010). Similarly, the ventral hippocampus preferentially innervates the ventromedial PFC, including the infralimbic PFC and the more ventral portion of the prelimbic PFC, suggesting another potential structure in a larger circuit by which ventral hippocampus projections may regulate response strategy selection.

Together with a growing literature identifying roles for the ventral hippocampus in the regulation of approach/avoidance behavior and context retrieval, our observations suggest that the ventral hippocampus may significantly contribute to the ability to flexibly regulate behavior in an adaptive manner. Interestingly, recent research indicates that the ventral hippocampus may be particularly susceptible to perturbations in early life and adolescence including impairments following chronic alcohol exposure (Almonte et al. 2017) or models of chronic stress (Barfield et al. 2017). These findings implicate the ventral hippocampus as a target that may contribute to the dysregulation of behavioral flexibility observed in neuropsychiatric illness, and as a substrate that may be directly impacted by factors that promote the development of these illnesses across the lifespan. 


\section{Materials and Methods}

\section{Subjects}

Adult male C57BL/6J mice were obtained from Jackson Laboratories and used in accordance with the University Institutional Animal Care and Use Committee guidelines. Mice were housed in the Medical University of South Carolina vivarium on a reverse $12 \mathrm{~h}: 12$ $\mathrm{h}$ light-dark cycle. All behavioral testing was performed during the dark cycle. Mice were food restricted to $90 \%$ of their free-feeding weights during behavioral testing. Water was available ad libitum for the duration of the study.

\section{Conditioning chambers}

Standard instrumental chambers housed within sound-attenuating boxes were used for these experiments (Med Associates). The side walls of the chambers were stainless steel panels, and the front door, ceiling, and back wall were clear Plexiglas. Chambers had house lights at the top middle panel on the right wall, above a magazine into which liquid reinforcers were delivered by syringe pump to the magazine. Reinforcer wells were equipped with lickometers. Retractable levers were extended during appropriate sessions on either side of the magazine. A fan provided ventilation and background noise.

\section{Surgery}

Prior to any training, mice underwent stereotaxic surgery for injection of an AAV expressing a Gi-coupled DREADD under control of a CaMKII $\alpha$ promoter (AAV8-CaMKII $\alpha$-hM4Di-mCherry; University of North Carolina Vector Core and Addgene. pAAV-CaMKIIahM4D(Gi)-mCherry was a gift from Bryan Roth (Addgene viral prep \#50477-AAV8; http://n2t.net/addgene:50477; RRID: Addgene_ 50477)). Virus was microinjected bilaterally into the ventral hippocampus (AP $-3.2 \mathrm{~mm}, \mathrm{ML} \pm 2.8 \mathrm{~mm}, \mathrm{DV}-4.0 \mathrm{~mm}$ ). Viral vectors were infused over $2 \mathrm{~min}$, with a 5 min diffusion period $(0.2 \mu \mathrm{L} /$ side). A subset of mice additionally had bilateral cannula (Plastics One) implanted targeting the nucleus accumbens shell ( $\mathrm{AP}+1.5$ $\mathrm{mm}, \mathrm{ML} \pm 0.6 \mathrm{~mm}, \mathrm{DV}-3.7 \mathrm{~mm}$ ). Cannula were secured to the skull using Metabond and dental cement. Surgeries were performed under isoflurane anesthesia. In order to control for off-target effects of systemic $\mathrm{CNO}$, one cohort of animals received a microinjection of a null virus, that did not express the Gi-DREADD (AAV2-hSyn-EYFP). These mice were treated identically. All mice were allowed to recover for at least 1 wk prior to food restriction.

\section{Instrumental training}

After recovery from surgery, mice were restricted to $90 \%$ of their free feeding weights. Each day, mice had a 30 min training session in which they were trained to perform a response for delivery of $20 \mu \mathrm{L}$ of a $10 \%$ sucrose solution. Two levers were presented. One lever was assigned to be an "active" lever, on which responding resulted in reinforcer delivery, and the other lever was assigned as an "inactive" lever, on which responding had no consequence. At the initiation of training, a press on the active lever was reinforced on a fixed ratio 1 (FR1) schedule during which each press resulted in a reinforcer delivery. After $3 \mathrm{~d}$ of $>20$ lever presses on the active lever, mice were graduated to a random interval (RI) 30 schedule. During these sessions, the first lever press after a randomly determined interval (averaging $30 \mathrm{sec}$ ) was reinforced. After three RI30 sessions, mice performed nine RI60 sessions before the beginning of habit testing. No drug or saline was delivered during task acquisition.

\section{Contingency degradation testing}

The ability to update behavior when action-outcome contingencies changed was assessed using a contingency degradation paradigm (Barker et al. 2013). The testing conditions during degradation testing were identical to training conditions, except that during the degraded sessions, delivery of the $10 \%$ sucrose reinforcer was no longer contingent upon a lever press. Rather, reinforcer delivery was determined by the number of reinforcers that each an- imal earned during the previous session in which the contingency was intact. Delivery was spaced equivalently across the 30-min session, and responses on the lever were recorded but did not have an outcome. Mice underwent four testing conditions: a Degraded Session and a Nondegraded Session (identical to training condition), with $\mathrm{CNO}$ and saline administered as described below. The order of these sessions was counterbalanced. This testing procedure enables assessment of increased sensitivity to changes in contingency often with only a single day of degradation training (Barker et al. 2013, 2014; Serlin and Torregrossa 2014; Butkovich et al. 2015). While other measures of contingency degradation may be of value in the future to clearly elucidate all sources of change in behavior, this paradigm was chosen as the ability to observe within-session reductions in behavior does not require memory consolidation which may also be altered by ventral hippocampus function.

\section{Drug administration}

In order to silence ventral hippocampus projections, the DREADD agonist clozapine-N-oxide (CNO; Cayman Chemical) was administered either systemically (i.p.) or locally into the nucleus accumbens shell. In systemic administration experiments, CNO was dissolved in sterile saline. $\mathrm{CNO}$ or saline were administered 30 min prior to test sessions (i.p., $2 \mathrm{mg} / \mathrm{kg}$ ). To control for the potential off-target effects of CNO that may result from metabolism into clozapine, one cohort of animals lacking the DREADD receptor received CNO or vehicle prior to degraded and nondegraded test sessions under conditions that were identical to those described above (MacLaren et al. 2016; Gomez et al. 2017; Mahler and Aston-Jones 2018; Manvich et al. 2018). In experiments examining the effect of selective inhibition of ventral hippocampus to nucleus accumbens shell projections, CNO was infused 10 min prior to each test session $(500 \mu \mathrm{M} ; 0.2 \mu \mathrm{L} /$ side). Infusions took place over a $2 \mathrm{~min}$ period and the infusion cannula was left in place for an additional $2 \mathrm{~min}$ to allow diffusion of the CNO. The order of drug administration was determined based on response rates and the order of drug versus vehicle administration was counterbalanced.

\section{Pavlovian training}

A subset of mice that had been trained to self-administer sucrose were trained in a cue-outcome association following the completion of habit testing. The same conditioning chambers used for operant self-administration were used in these studies, but levers were retracted. During 30 min sessions, a previously neutral cue (tone) was associated with the delivery of a $10 \%$ sucrose solution. Mice did not receive saline or vehicle injections during training. During these sessions, the tone was played on a fixed time schedule (120 sec off, $60 \mathrm{sec}$ on). Twenty microliters of sucrose was delivered during each "cue-on" period on a random time schedule so that sucrose delivery could not be anticipated. No sucrose was delivered during "cue-off" intervals. No response was required to initiate reward delivery, and sucrose delivery was not contingent on behavior. Licks at the magazine were recorded during the cue-on and cue-off intervals. After acquisition, mice underwent a single test session during which CNO or vehicle were administered systemically as described above.

\section{Extinction}

A subset of mice that had undergone habit testing were retrained in the absence of $\mathrm{CNO}$ or saline injections in sessions in which the RI60 contingency was intact (i.e., the action-outcome relationship was in place). After establishing stable responding, mice were assigned based on response rates to receive either $\mathrm{CNO}$ or saline injections (i.p.) during an extinction protocol; mice received the same drug across extinction days. On the day prior to extinction training (day 0 ), mice received an injection of CNO or saline 30 min prior to an RI60 session in which the contingency was in place. On the first day of extinction (extinction day 1), mice received an injection of the same drug assigned on day 0 (CNO or saline) $30 \mathrm{~min}$ prior to being tested in extinction. Conditions were 
identical to training except that while lever presses resulted in the pumps turning on under the same RI60 contingency as during training, no sucrose was delivered. Mice received six sessions of extinction training.

\section{Histology}

After testing was complete, mice were sacrificed via rapid decapitation and brains were post-fixed in $4 \%$ PFA for $24 \mathrm{~h}$, and cryoprotected in a 30\% sucrose solution for at least $48 \mathrm{~h}$. Virus expression and placement was confirmed by assessment of mCherry or EYFP expression. Cannula placement was confirmed by identifying tract placement. Tissue from a subset of animals underwent immunofluorescent processing to generate images for this manuscript. Tissue was harvested as before, via rapid decapitation, and underwent post-fixing and cryoprotection in sucrose prior to slicing at $40 \mu \mathrm{m}$. Sections were incubated overnight in a rabbit anti-DsRed primary antibody (1:500; Living Colors) and visualized using an AlexaFluor-594 conjugated donkey anti-rabbit secondary antibody (1:250; Jackson ImmunoResearch).

\section{Statistical analyses}

All statistical analysis was performed using SPSS. Training and testing data were analyzed using rmANOVA, with $P<0.05$ considered significant. $\mathrm{CNO}$ administration was analyzed as a within-subject variable for habit and cue-mediated behavior experiments, but as a between-subjects for extinction data. Significant interactions were followed by Bonferroni corrected $t$-tests. A subset of rmANOVA results were Greenhouse-Geisser corrected for violations of sphericity.

\section{Acknowledgments}

This work was supported by National Institutes of Health grants AA024499 (J.M.B.), AA019967 (L.J.C.), AA022701 (L.J.C.), and AA010761 (L.J.C.). The authors thank Lauren Plyler for her expert technical assistance.

\section{References}

Almonte AG, Ewin SE, Mauterer MI, Morgan JW, Carter ES, Weiner JL. 2017. Enhanced ventral hippocampal synaptic transmission and impaired synaptic plasticity in a rodent model of alcohol addiction vulnerability. Sci Rep 7: 12300. doi:10.1038/s41598-017-12531-z

Barfield ET, Gerber KJ, Zimmermann KS, Ressler KJ, Parsons RG, Gourley SL. 2017. Regulation of actions and habits by ventral hippocampal trkB and adolescent corticosteroid exposure. PLoS Biol 15: e2003000. doi:10.1371/journal.pbio.2003000

Barker JM, Taylor JR. 2016. Habitual alcohol seeking: modeling the transition from casual drinking to addiction. Neurosci Biobehav Rev 47: 281-294. doi:10.1016/j.neubiorev.2014.08.012

Barker JM, Torregrossa MM, Taylor JR. 2013. Bidirectional modulation of infralimbic dopamine D1 and D2 receptor activity regulates flexible reward seeking. Front Neurosci 7: 126. doi:10.3389/ fnins.2013.00126

Barker JM, Zhang H, Villafane JJ, Wang TL, Torregrossa MM, Taylor JR. 2014. Epigenetic and pharmacological regulation of 5HT3 receptors controls compulsive ethanol seeking in mice. Eur J Neurosci 39: 999-1008. doi:10.1111/ejn.12477

Barker JM, Glen WB, Linsenbardt DN, Lapish CC, Chandler LJ. 2017. Habitual behavior is mediated by a shift in response-outcome encoding by infralimbic cortex. eNeuro 4: ENEURO.0337-17.2017. doi:10.1523/ ENEURO.0337-17.2017

Britt JP, Benaliouad F, McDevitt RA, Stuber GD, Wise RA, Bonci A. 2012. Synaptic and behavioral profile of multiple glutamatergic inputs to the nucleus accumbens. Neuron 76: 790-803. doi:10.1016/j. neuron.2012.09.040

Butkovich LM, DePoy LM, Allen AG, Shapiro LP, Swanson AM, Gourley SL. 2015. Adolescent-onset GABA A $\alpha 1$ silencing regulates reward-related decision making. Eur J Neurosci 42: 2114-2121. doi:10.1111/ejn.12995

Corbit LH, Balleine BW. 2000. The role of the hippocampus in instrumental conditioning. J Neurosci 20: 4233-4239. doi:10.1523/ JNEUROSCI.20-11-04233.2000
Coutureau E, Killcross S. 2003. Inactivation of the infralimbic prefrontal cortex reinstates goal-directed responding in overtrained rats. Behav Brain Res 146: 167-174. doi:10.1016/j.bbr.2003.09.025

Everitt BJ, Robbins TW. 2015. Drug addiction: updating actions to habits to compulsions ten years on. Annu Rev Psychol 67: 23-50. doi:10.1146/ annurev-psych-122414-033457

Gillan CM, Apergis-Schoute AM, Morein-Zamir S, Urcelay GP, Sule A, Fineberg NA, Sahakian BJ, Robbins TW. 2015. Functional neuroimaging of avoidance habits in obsessive-compulsive disorder. Am J Psychiatry 172: 284-293. doi:10.1176/appi.ajp.2014.14040525

Gomez JL, Bonaventura J, Lesniak W, Mathews WB, Sysa-Shah P, Rodriguez LA, Ellis RJ, Richie CT, Harvey BK, Dannals RF, et al.. 2017. Chemogenetics revealed: DREADD occupancy and activation via converted clozapine. Science 357: 503-507. doi:10.1126/science. aan 2475

Gourley SL, Lee AS, Howell JL, Pittenger C, Taylor JR. 2010. Dissociable regulation of instrumental action within mouse prefrontal cortex. Eur J Neurosci 32: 1726-1734. doi:10.1111/j.1460-9568.2010.07438.x

Gourley SL, Olevska A, Zimmermann KS, Ressler KJ, Dileone RJ, Taylor JR. 2013. The orbitofrontal cortex regulates outcome-based decision-making via the lateral striatum. Eur J Neurosci 38: 2382-2388. doi:10.1111/ejn.12239

Gremel CM, Costa RM. 2013. Orbitofrontal and striatal circuits dynamically encode the shift between goal-directed and habitual actions. Nat Commun 4: 2264. doi:10.1038/ncomms3264

Ishikawa A, Nakamura S. 2003. Convergence and interaction of hippocampal and amygdalar projections within the prefrontal cortex in the rat. J Neurosci 23: 9987-9995. doi:10.1523/ JNEUROSCI.23-31-09987.2003

Ito R, Lee ACH. 2016. The role of the hippocampus in approach-avoidance conflict decision-making: evidence from rodent and human studies. Behav Brain Res 313: 345-357. doi:10.1016/j.bbr.2016.07.039

Killcross S, Coutureau E. 2003. Coordination of actions and habits in the medial prefrontal cortex of rats. Cereb Cortex 13: 400-408. doi:10.1093/ cercor/13.4.400

Krause M, German PW, Taha SA, Fields HL. 2010. A pause in nucleus accumbens neuron firing is required to initiate and maintain feeding. J Neurosci 30: 4746-4756. doi:10.1523/JNEUROSCI.0197-10.2010

MacLaren DAA, Browne RW, Shaw JK, Krishnan Radhakrishnan S, Khare P, España RA, Clark SD. 2016. Clozapine N-oxide administration produces behavioral effects in Long-Evans rats: implications for designing DREADD experiments. eNeuro 3: ENEURO.0219-16.2016. doi:10.1523/ ENEURO.0219-16.2016

Mahler SV, Aston-Jones G. 2018. CNO evil? Considerations for the use of DREADDs in behavioral neuroscience. Neuropsychopharmacology 43: 934-936. doi:10.1038/npp.2017.299

Manvich DF, Webster KA, Foster SL, Farrell MS, Ritchie JC, Porter JH, Weinshenker D. 2018. The DREADD agonist clozapine N-oxide (CNO) is reverse-metabolized to clozapine and produces clozapine-like interoceptive stimulus effects in rats and mice. Sci Rep 8: 3840. doi:10.1038/s41598-018-22116-z

Millan EZ, Kim HA, Janak PH. 2017. Optogenetic activation of amygdala projections to nucleus accumbens can arrest conditioned and unconditioned alcohol consummatory behavior. Neuroscience 360: 106-117. doi:10.1016/j.neuroscience.2017.07.044

Ouhaz Z, Ba-M'hamed S, Bennis M. 2014. Haloperidol treatment at pre-exposure phase reduces the disturbance of latent inhibition in rats with neonatal ventral hippocampus lesions. C R Biol 337: 561-570. doi:10.1016/J.CRVI.2014.07.005

Pennartz CMA, Ito R, Verschure PF, Battaglia FP, Robbins TW. 2011. The hippocampal-striatal axis in learning, prediction and goal-directed behavior. Trends Neurosci 34: 548-559. doi:10.1016/j. tins.2011.08.001

Pezzulo G, van der Meer MA, Lansink CS, Pennartz CM. 2014. Internally generated sequences in learning and executing goal-directed behavior. Trends Cogn Sci 18: 647-657. doi:10.1016/j.tics.2014.06.011

Riaz S, Schumacher A, Sivagurunathan S, Van Der Meer M, Ito R. 2017. Ventral, but not dorsal, hippocampus inactivation impairs reward memory expression and retrieval in contexts defined by proximal cues. Hippocampus 27: 822-836. doi:10.1002/hipo.22734

Schmajuk NA, Cox L, Gray JA. 2001. Nucleus accumbens, entorhinal cortex and latent inhibition: a neural network model. Behav Brain Res 118: 123-141. doi:10.1016/S0166-4328(00)00319-3

Serlin H, Torregrossa MM. 2014. Adolescent rats are resistant to forming ethanol seeking habits. Dev Cogn Neurosci 16: 183-190. doi:10.1016/j. dcn.2014.12.002

Sjoerds Z, de Wit S, van den Brink W, Robbins TW, Beekman AT, Penninx BW, Veltman DJ. 2013. Behavioral and neuroimaging evidence for overreliance on habit learning in alcohol-dependent patients. Transl Psychiatry 3: e337. doi:10.1038/tp.2013.107 
Smith KS, Graybiel AM. 2013. A dual operator view of habitual behavior reflecting cortical and striatal dynamics. Neuron 79: 361-374. doi:10.1016/j.neuron.2013.05.038

Smith KS, Virkud A, Deisseroth K, Graybiel AM. 2012. Reversible online control of habitual behavior by optogenetic perturbation of medial prefrontal cortex. Proc Natl Acad Sci 109: 18932-18937. doi:10.1073/ pnas.1216264109

Tran-Tu-Yen DA, Marchand AR, Pape JR, Di Scala G, Coutureau E. 2009. Transient role of the rat prelimbic cortex in goal-directed behaviour. Eur J Neurosci 30: 464-471. doi:10.1111/j.1460-9568.2009.06834.x

Weiner I, Feldon J. 1997. The switching model of latent inhibition: an update of neural substrates. Behav Brain Res 88: 11-25. doi:10.1016/ S0166-4328(97)02314-0
Yin HH, Knowlton BJ, Balleine BW. 2004. Lesions of dorsolateral striatum preserve outcome expectancy but disrupt habit formation in instrumental learning. Eur J Neurosci 19: 181-189.

Yin HH, Ostlund SB, Knowlton BJ, Balleine BW. 2005. The role of the dorsomedial striatum in instrumental conditioning. Eur J Neurosci 22: 513-523. doi:10.1111/j.1460-9568.2005.04218.x

Yin HH, Knowlton BJ, Balleine BW. 2006. Inactivation of dorsolateral striatum enhances sensitivity to changes in the action-outcome contingency in instrumental conditioning. Behav Brain Res 166: 189-196. doi:10.1016/j.bbr.2005.07.012

Received June 11, 2018; accepted in revised form November 10, 2019. 


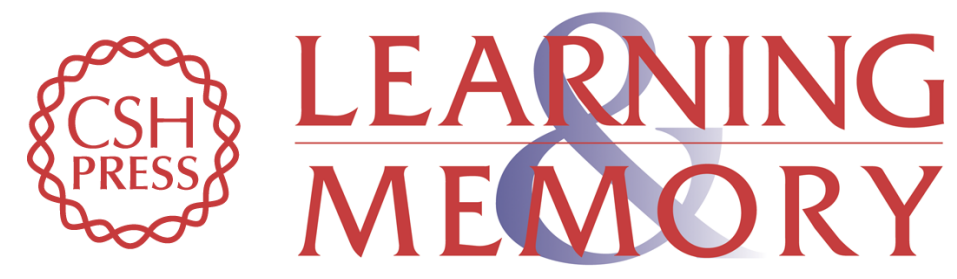

\section{Inactivation of ventral hippocampus projections promotes sensitivity to changes in contingency}

Jacqueline M. Barker, Kathleen G. Bryant and L. Judson Chandler

Learn. Mem. 2019, 26:

Access the most recent version at doi:10.1101//m.048025.118

References This article cites 38 articles, 7 of which can be accessed free at: http://learnmem.cshlp.org/content/26/1/1.full.html\#ref-list-1

Creative This article is distributed exclusively by Cold Spring Harbor Laboratory Press for the Commons License first 12 months after the full-issue publication date (see

http://learnmem.cshlp.org/site/misc/terms.xhtml). After 12 months, it is available under a Creative Commons License (Attribution-NonCommercial 4.0 International), as described at http://creativecommons.org/licenses/by-nc/4.0/.

Email Alerting Receive free email alerts when new articles cite this article - sign up in the box at the Service top right corner of the article or click here. 